\title{
Synthesis and characterization of zeolite NaY using local rice husk as a source of silica and removal of $\mathrm{Cr}(\mathrm{VI})$ from wastewater by zeolite
}

\author{
A. K. Ghosh ${ }^{3}$, S. Ahmed ${ }^{2}$ and M. Y. A. Mollah ${ }^{1 *}$ \\ ${ }^{1}$ Department of Chemistry, University of Dhaka, Dhaka-1000, Bangladesh \\ ${ }^{2}$ Institute of Glass and Ceramic Research and Testing (IGCRT), Bangladesh Council of Scientific and Industrial \\ Research (BCSIR), Dhaka-1205, Bangladesh \\ ${ }^{3}$ Department of Chemistry, Jahangirnagar University, Savar, Dhaka, Bangladesh
}

\begin{abstract}
The Zeolite $\mathrm{NaY}$ in pure phase was synthesized from rice husk $(\mathrm{RH})$ following a three step synthetic route. In the preliminary step seed gel was prepared from a mixture of silicate and Na-acetate solution. This step was then followed by the preparation of feedstock gel. The third or final step involved the mixing of seed gel (5\%) and feedstock gel (95\%) which produced the zeolite of desired phase, NaY. The synthesized zeolite was characterized by FT-IR, XRD, SEM and DLS particle size analyzer and used to treat wastewater containing Cr (VI). The adsorption of $\mathrm{Cr}(\mathrm{VI})$ was monitored as a function of $\mathrm{pH}$ of the solution, contact time and initial concentration of $\mathrm{Cr}(\mathrm{VI})$. The adsorption results revealed that after scaling up the methodology, the synthesized zeolite NaY could be used as a promising cost-effective adsorbent for the treatment of wastewater containing chromium.
\end{abstract}

Keywords: Rice Husk; Silica; Aluminosilicate; Zeolite NaY; Chromium

\section{Introduction}

Rice husk ( $\mathrm{RH})$ is an agricultural waste and during milling of paddy $c a .22 \%$ of the weight of paddy is left as husk (Aderolu et. al., 2007). The husk contains about $70-75 \%$ volatile organic matters while the rest is hydrated silica (Park, 2003; Williams et. al., 2000). Rice husk is generally used in rural areas as a source of fuel for cooking and as animal feeds. However, due to the presence of significant percentage of silica in $\mathrm{RH}$, considerable attention has been given to utilize RH for producing pure silica (Riveros et. al., 1986), silicon carbide and zeolites (Jan-Jerrel et. al., 2011) as well as a pozzolanic material (Ramezanianpour et. al., 2009), as an adsorbent (Wahab et. al., 2005) etc.

Rice husk ash (RHA) produced during controlled burning of husk at a temperature of $\sim 550^{\circ} \mathrm{C}$ (Wittayakun et. al., 2008) is enriched with amorphous silica ( $c a .85$ - $90 \%$ ). The utilization of RHA as an alternative source of silica towards the synthesis of zeolites has been reported nearly 24 years ago (Bajpai et. al., 1978). They have synthesized mordenite type zeolite using silica from RHA. However, in addition to this, researchers throughout the world have made a significant contribution in synthesizing different types of zeolites e.g. MOR, NaX, Beta, ZSM-5, ZSM-48, and FSM-16 using this silica source (Wang et. al., 1998; Katsuki et. al., 2005; Prasetyoko et. al., 2005; Dalal and Rao, 1985).

Zeolite is a microporous crystalline material which consists of hydrated aluminosilicates composed of tetrahedral $\mathrm{TO}_{4}$ units ( $\mathrm{T}=\mathrm{Si}$ or $\mathrm{Al})$ which are inter linked by oxygen atoms. According to (Jobic, 1992): "A zeolite is an aluminosilicate with a framework structure enclosing cavities occupied by large ions and water molecules, both of which have considerable freedom of movement permitting ion exchange and reversible dehydration". The general formula of zeolite is represented by $\mathrm{M}_{\mathrm{a}}{ }^{\mathrm{n}+}\left[\mathrm{Si}_{\mathrm{x}} \mathrm{Al}_{\mathrm{y}} \mathrm{O}_{\mathrm{z}}\right] \cdot \mathrm{mH}_{2} \mathrm{O}$ where $\mathrm{M}^{\mathrm{n}+}$ is the cation; $\left[\mathrm{Si}_{\mathrm{x}} \mathrm{Al}_{\mathrm{y}} \mathrm{O}_{\mathrm{z}}\right]$ is zeolite framework while $\mathrm{mH}_{2} \mathrm{O}$ is water molecule present in sorbed phase (Roberie, 2001). Both natural and synthesized zeolites find use as molecular sieves (Haggerty and Bowman, 1994). Zeolites exhibit high sorption capacity for inorganic cations including heavy metals (Curkovik et. al., 1997 and Mier et. al., 2001) and ammonium (Semmens and Goodrich, 1977).

Bangladesh is a developing country where discharge of industrial waste is a major problem. Particularly, the tannery industries are playing a major role in polluting the surface water through direct release of the toxic, hazardous wastes

\footnotetext{
*Corresponding author. e-mail: myamollah@hotmail.com
} 
(containing excess chromium salts) into the rivers and/or in nearby ponds. Although the tannery sector is the fourth largest foreign exchange earner of the country and contributes about six per cent of total export earnings, it is also responsible for significant water pollution. Tanneries in the city's Hazaribagh area discharge huge amount of liquid toxic wastes containing chromium everyday. Hence, considering the wastewater scenario of tannery industries of Hazaribagh in Bangladesh, an attempt has been made to remove chromium (VI) from waste water using the zeolite, synthesized from RHA. Such an attempt is expected to be beneficial in two ways: (i) A cost effective and easy approach will be facilitated to remove $\mathrm{Cr}(\mathrm{VI})$ from tannery wastewater and (ii) utilization of RHA will be a promising material recycling technology for future waste management.

\section{Materials and methods}

\section{Chemicals}

Analar grade $\mathrm{NaOH}, \mathrm{NaAlO}_{2}, \mathrm{~K}_{2} \mathrm{Cr}_{2} \mathrm{O}_{7}$ were purchased either from $\mathrm{BDH}$, UK or E. Merk Germany and used as received. RH was collected from Biswas Rice Mill, Sutrujitpur, Magura. All the solutions of desired concentrations were prepared using double distilled water.

\section{Method}

The experimental method comprised the following three steps: (a) Preparation of amorphous Si from RH; (b) Synthesis of zeolite, NaY using prepared silica ( $\mathrm{Si}$ ); and (c) Treatment of wastewater containing chromium using the synthesized zeolite $\mathrm{NaY}$.

\section{(a) Preparation of amorphous Si from $\mathrm{RH}$}

Prior to burning, the rice husk was washed three times by distilled water and then soaked in $1 \% \mathrm{H}_{2} \mathrm{SO}_{4}$ for 24 hours. Rice husk was then washed repeatedly with distilled water to remove acid and it was dried at normal temperature and pressure. The dried rice husk was then burnt in a Tube Furnace at a constant temperature of $650^{\circ} \mathrm{C}$ under usual atmospheric pressure for an hour to ensure that the product is in amorphous silica phase. The product was obtained in the form of blackish powder. It was then further burnt in a Muffle Furnace at $650^{\circ} \mathrm{C}$ for six hours to obtain the white ash. The rice husk ash was ground using a mortar to homogenize and to obtain a powdered form of the material.

\section{(b) Synthesis of zeolite, NaY using prepared silica}

Sodium aluminate, sodium hydroxide $(\mathrm{NaOH})$ pellets and silica from RHA were used as the raw materials to synthesize zeolite NaY. The synthesis was accomplished by following the method of Ginter, D. M. (Ginter et. al., 1992) but the compositions and types of raw materials were different. The overall method comprised three steps; at first seed gel was prepared which was followed by the second step feedstock gel while the final step was the preparation of overall gel.

Preparation of seed gel

Seed gel was prepared from a mixture of aluminate and silicate solution. At first $\mathrm{NaOH}$ solution was prepared by dissolving a requisite amount of the pellets in deionized water. This $\mathrm{NaOH}$ solution was then mixed with the sodium aluminate, $\mathrm{NaAlO}_{2}$ solution to prepare the aluminate solution. The mixture was then heated gently under continuous stirring condition until it turned into solution. On the other hand, silicate solution was prepared by dissolving the silica (obtained from RHA) in $\mathrm{NaOH}$ solution. It was then stirred and heated in the water bath maintaining the water at boiling temperature. The aluminate and silicate were then mixed in a Teflon beaker and stirred until it became homogeneous. At this stage, the mixture was transferred into an airtight Teflon bottle and kept for ageing at room temperature for 24 hours. After 24 hours of ageing, the loose brown gel appeared which was used as seed gel. Seed gel contributed $5 \%$ of the overall gel composition.

Preparation of feedstock gel

The second step was the preparation of feedstock gel which comprised $95 \%$ of the whole gel composition. The preparation step was similar to that of the seed gel but different in the quantity of starting materials used. Moreover no ageing step was followed, i.e. it was used immediately after the preparation.

Preparation of overall gel

Finally, the overall gel was prepared by mixing the feedstock gel $(95 \%)$ and seed gel (5\%). The feedstock gel was stirred magnetically and at the same time the seed gel was added slowly and the mixture was continuously stirred for 2 hours. The mixture was then transferred into the airtight Teflon bottle and left for ageing for 24 hours at room temperature. After the completion of the ageing step the mixture was kept 
in an oven at $100^{\circ} \mathrm{C}$ for 24 hours. The Teflon bottle was then taken out and the cap was quickly opened to cool it at room temperature. At this stage, the solid product formed was separated by suction filtration and followed by washing with hot deionized water and then dried overnight in the oven at $100^{\circ} \mathrm{C}$. The flowchart of the entire preparation procedure is shown in Fig. 1. This synthesized zeolite NaY was then characterized using x-ray diffractometer (XRD), fourier transform infrared spectrometer (FT-IR), scanning electron microscope (SEM) equipped with energy dispersive system and particle size analyzer. After completing the characterization, zeolite $\mathrm{NaY}$ was used to treat the chromium containing water.
Prestige 21 (SHIMADZU). Sample to $\mathrm{KBr}$ ratio of 1:100 was used to obtain experimental spectra and the sample was scanned in the mid-infrared wave number range of 4000$400 \mathrm{~cm}^{-1}$ with an average of 25 scans. The resolution of the spectrometer was $2 \mathrm{~cm}^{-1}$.

SEM images were recorded by JEOL - JSM 6490OLA scanning electron microscope (SEM) equipped with energy dispersive spectrometer (EDS). The sample was mounted with double sided tape and electrically conducted by coating with metal in AGAR AUTO Sorption COATYER.

Particle size distribution of the zeolite $\mathrm{NaY}$ was determined by the Zetasizer Nano Series equipment (Malvern

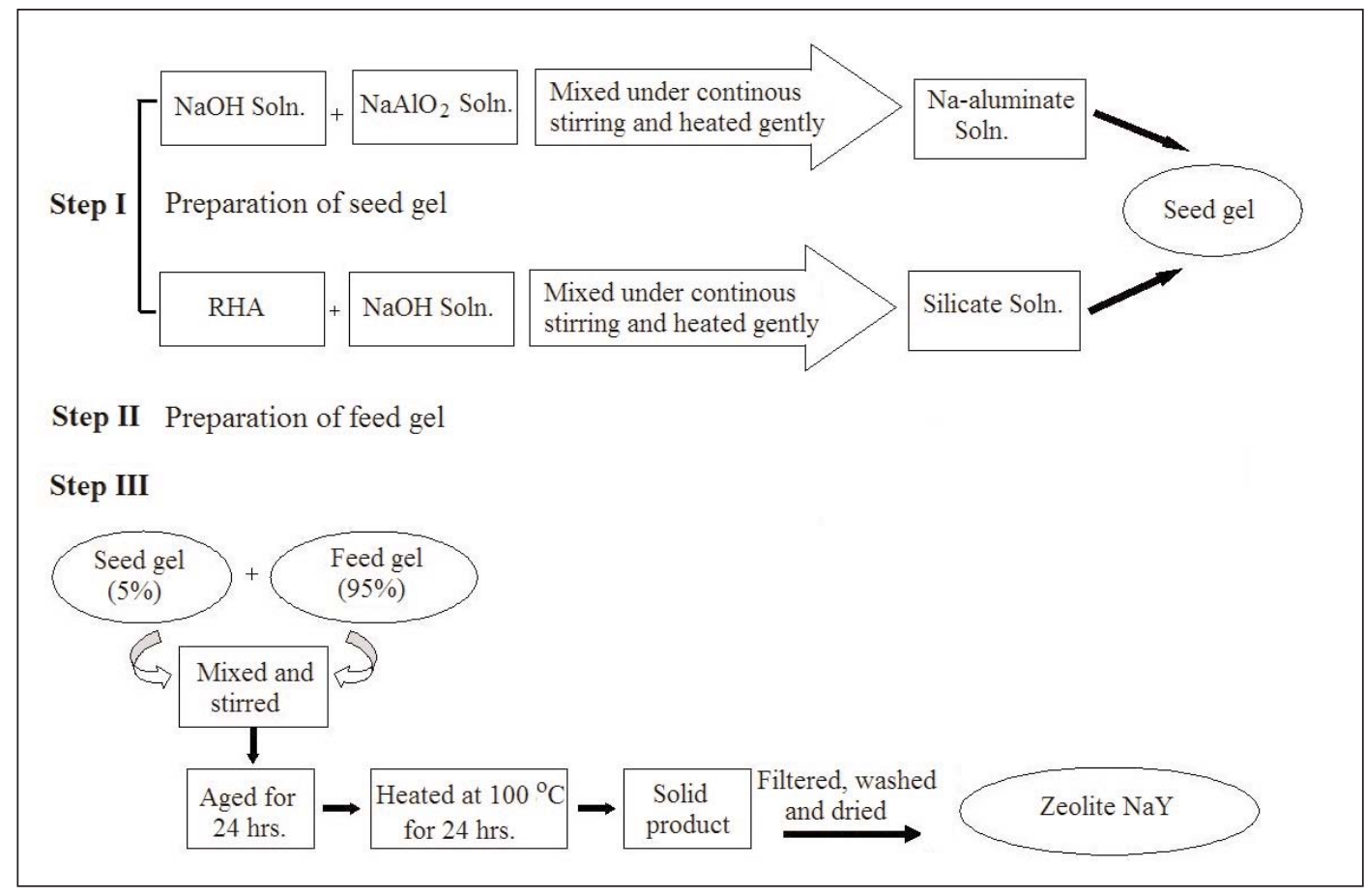

Fig. 1. Flowchart of the zeolite NaY synthesis procedure from RHA

Characterization of the synthesized zeolite $\mathrm{NaY}$

Phase analysis of the synthesized zeolite $\mathrm{NaY}$ was performed by X-ray diffraction spectrophotometer (PANalytical X'Pert PRO XRD PW 3040). The intensity data was collected in $0.02^{\circ}$ steps at the scanning range of $2 \theta=10^{\circ}$ to $90^{\circ}$ using $\mathrm{CuK}_{\alpha}(\lambda=1.54178 \AA)$ radiation source. The sample was ground to fine powder and loaded into the stainless steel (SS) sample holder. The observed data was compared with the standard data.

The functional groups present in the synthesized zeolite $\mathrm{NaY}$ were identified by recording the FT-IR peaks using FT-IR
Instrument Ltd., England) based on Dynamic Light Scattering (DLS).

Treatment of chromium containing wastewater using zeolite $\mathrm{NaY}$

The stock solution $\left(1,000 \mathrm{mg} \mathrm{L}^{-1}\right)$ of $\mathrm{Cr}(\mathrm{VI})$ was prepared by dissolving requisite amount of $\mathrm{K}_{2} \mathrm{Cr}_{2} \mathrm{O}_{7}$ in deionized water and diluted to the desired concentration range (2-100 $\mathrm{mg} \mathrm{L}^{-1}$ ). The concentrations of $\mathrm{Cr}(\mathrm{VI})$ were measured by Atomic absorption spectrophotometer (AAS, PERKIN ELMER USA; Model - A Analyst 800). The adsorption effi- 
ciency of the synthesized zeolite $\mathrm{NaY}$ was then examined by monitoring the concentration of $\mathrm{Cr}(\mathrm{VI})$ in the substrate solution as a function of adsorbent-solution contact time, initial concentration of $\mathrm{Cr}(\mathrm{VI})$ and $\mathrm{pH}$ of the of the substrate solution.

\section{Effect of adsorbent-solution contact time}

Six reagent bottles were charged with $50 \mathrm{~mL} \mathrm{Cr}$ (VI) solution of $10 \mathrm{mg} \mathrm{L}^{-1}$ concentration and the $\mathrm{pH}$ of each sample was adjusted at 2.0. A fixed amount $(0.5 \mathrm{~g})$ of zeolite $\mathrm{NaY}$ was added to each bottle and shaken well at room temperature. After different time intervals $(0,10,30,60,180$ and 360 $\mathrm{min}$ ), the reaction mixtures were separated by filtering and the concentrations of residual $\mathrm{Cr}$ (VI) in the supernatant solutions were measured by the AAS.

\section{Effect of initial Cr(VI) concentration}

Effect of initial Cr(VI) concentration on the removal of $\mathrm{Cr}(\mathrm{VI})$ was investigated at room temperature with initial concentrations of $\mathrm{Cr}$ (VI) as 2.0, 11.0, 21.0 and $106.0 \mathrm{mg}$ $\mathrm{L}^{-1}$ using $0.5 \mathrm{~g}$ zeolite $\mathrm{NaY}$ as adsorbent. The $\mathrm{pH}$ was adjusted at 2.0. The adsorption was allowed for $180 \mathrm{mins}$.

\section{Effect of $p H$}

The effect of $\mathrm{pH}$ was studied by varying the initial $\mathrm{pH}$ ranges from 2.0 - 7.0 by adjusting the $\mathrm{pH}$ with $0.1 \mathrm{M} \mathrm{NaOH}$ and 0.1 $\mathrm{M} \mathrm{HCl}$. A fixed amount $(0.5 \mathrm{~g})$ of the synthesized zeolite $\mathrm{NaY}$ was added to $50 \mathrm{~mL} \mathrm{Cr}$ (VI) solution having the desired $\mathrm{pH}$. The concentration of each $\mathrm{Cr}$ (VI) solution was maintained at $10 \mathrm{mg} \mathrm{L}^{-1}$. The solutions were shaken well in the reagent bottles and after $60 \mathrm{~min}$ each of the reaction mixture was filtered. The concentration of $\mathrm{Cr}(\mathrm{VI})$ in the filtered solutions were measured by AAS.

However in each case the adsorption efficiency of zeolite $\mathrm{NaY}$ was calculated by using the following equation.

$$
\% \text { of Adsorption }=\frac{A_{0}-A_{t}}{A_{t}} \times 100
$$

where $A_{0}$ is the initial concentration of $\mathrm{Cr}(\mathrm{VI})$ solution and $A_{\mathrm{t}}$ is the concentration after treatment.

\section{Results and discussion}

\section{Characterization of prepared RHA by XRD and SEM}

A typical XRD pattern of pure RHA is shown in Fig. 2. A broad peak at $2 \theta$ position $\sim 22^{\circ}$ is clearly observed in the diffractogram (Fig. 2.) which is characteristic of amorphous silica (Wittayakun et. al., 2008). This form of silica is suitable for Zeolite synthesis because it dissolves easily in $\mathrm{NaOH}$ to form sodium silicate (Wittayakun et. al., 2008). The SEM image (x100 magnifications, Fig. 3) of the prepared RHA shows that the particle size of the RHA was not uniform.

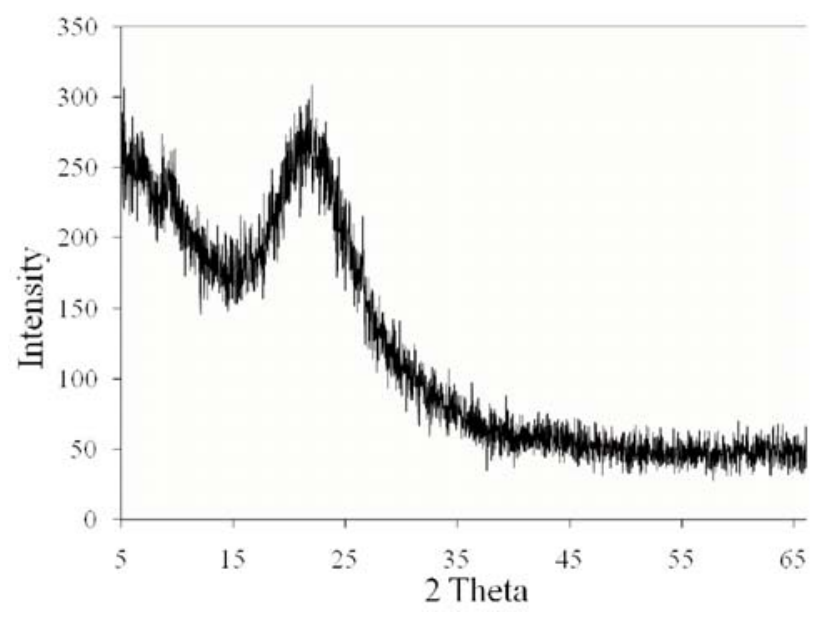

Fig. 2 XRD pattern of RHA

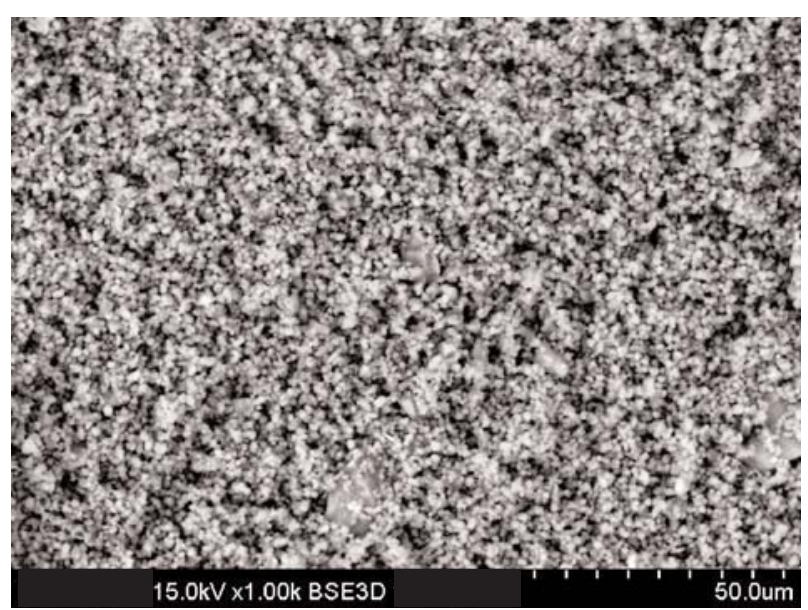

Fig. 3. SEM image of RHA

Characterization of the synthesized zeolite NaY by EDX, $X R D, F T-I R$ and SEM

The recorded EDX spectrum of the synthesized zeolite $\mathrm{NaY}$ is shown in Fig. 4, which clearly shows the presence of the expected elements $\mathrm{Si}, \mathrm{Al}, \mathrm{Na}$ and $\mathrm{O}$. However, the XRD diffractogram validated the presence of the desired phase in the prepared zeolite. 


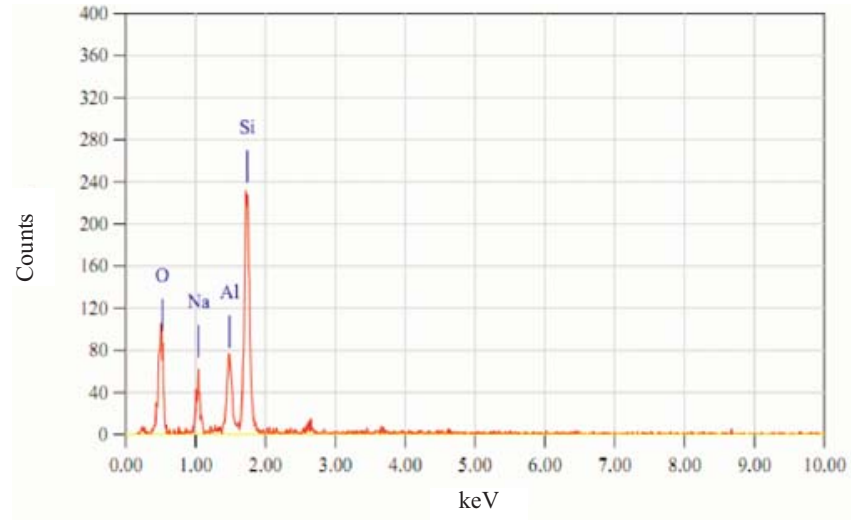

Fig. 4. EDX spectrum of zeolite $\mathrm{NaY}$

The diffractogram (Fig. 5) of the zeolite NaY synthesized by the seeding and ageing techniques exhibit prominant peaks at $2 \theta$ positions $5^{\circ}-70^{\circ}$ which are characteristic of zeolite $\mathrm{NaY}$. However, the observed result revealed that the synthesized zeolite $\mathrm{NaY}$ has formed in mixed phases; i.e. both amorphous and crystalline phase are present.

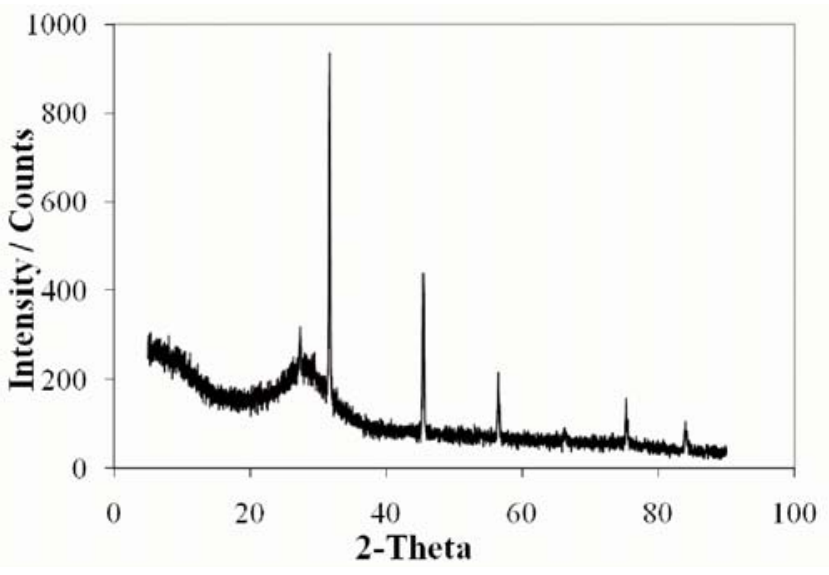

Fig. 5. XRD image of Zeolite NaY

The FT-IR spectrum of the zeolite $\mathrm{NaY}$ is illustrated in the Fig. 6 which shows the presence of strong IR absorption bands in the spectral region below $1200 \mathrm{~cm}^{-1}$. Since the mid FT-IR region of zeolite $\mathrm{NaY}$ exhibits the fundamental vibrations of $(\mathrm{Si}, \mathrm{Al}) \mathrm{O}_{4}$ tetrahedra framework, so the mid FT-IR region of the spectrum was considered (1300 to $\left.400 \mathrm{~cm}^{-1}\right)$ for analysis of $\mathrm{NaY}$. Vibration frequencies of the zeolite lattice result from stretching and bending modes of the T-O bands and are observed in the range 400 to $1200 \mathrm{~cm}^{-1}$ $\left(457.13 \mathrm{~cm}^{-1}\right.$ and $\left.1029.99 \mathrm{~cm}^{-1}\right)$. This observation confirmed that $\mathrm{SiO}_{4}$ or $\mathrm{AlO}_{4}$ are linked (Rahman et. al., 2009). The broad bands observed at $3446.79 \mathrm{~cm}^{-1}$ and $1648.27 \mathrm{~cm}^{-1}$ are due to tortuous vibration and convalent vibration respectively (Liu et. al., 2003).

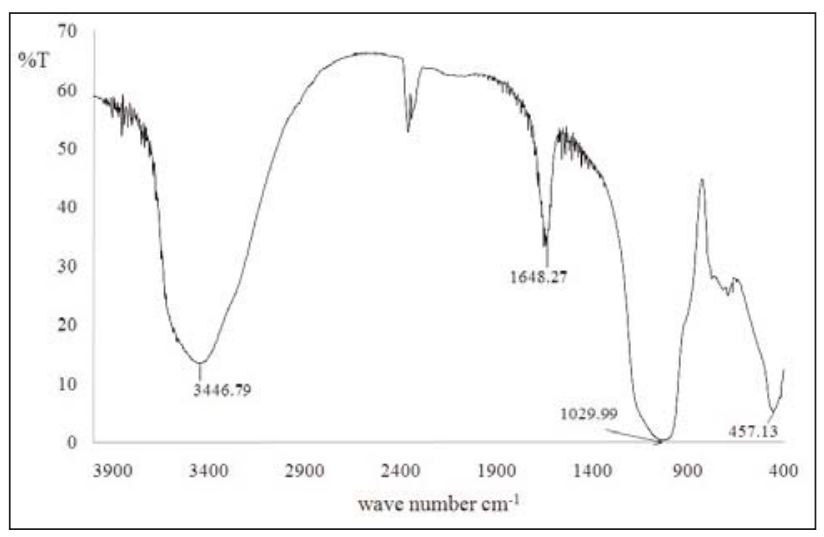

Fig. 6. FT-IR spectrum of Zeolite NaY

The SEM image of synthesized Zeolite $\mathrm{NaY}$ with magnification of $\times 200$ is illustrated in Fig. 7 which shows irregular morphology having various sizes and shapes (i.e. octahedral, twined etc.). It appears that, several crystals are fused together in agglomerated form.

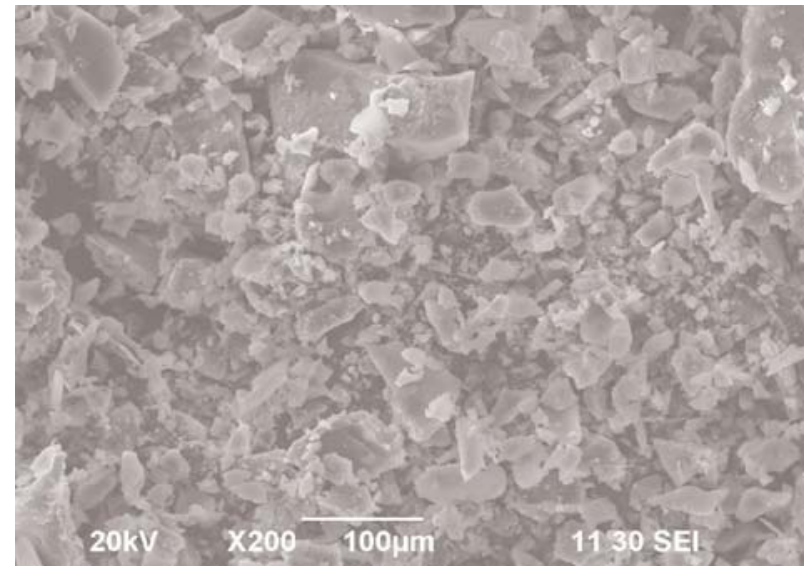

Fig. 7. SEM image of prepared zeolite NaY

Determination of particle size distribution of zeolite NaY

The particle size distribution and the statistics of distribution of the zeolite $\mathrm{NaY}$ is given in (Fig. 8). The major population $(56.2 \%)$ had a particle size in the range $255-295 \mathrm{~nm}$. There are smaller particles of sizes $190 \mathrm{~nm} \mathrm{(3 \% ),} 220.2 \mathrm{~nm}$ (15.4\%), $342 \mathrm{~nm}(19.2 \%)$ and $396.1 \mathrm{~nm}(6.2 \%)$. It may, however, be pointed out that the particle sizes determined from the Dynamic Light Scattering (DLS) measurements represent the size and distribution of bulk particles that might be composed of aggregates of smaller particles, as well. 


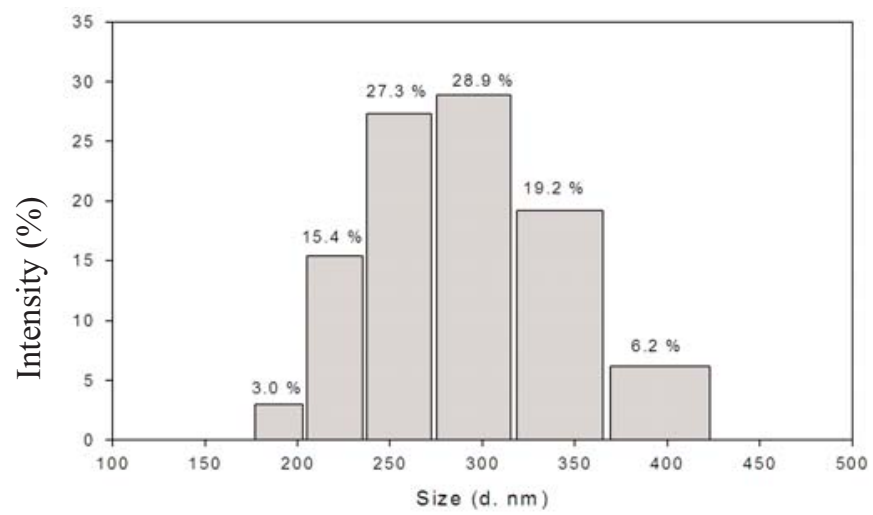

Fig. 8. Particle size distribution of zeolite $\mathrm{NaY}$

Treatment of chromium containing wastewater using zeolite $\mathrm{NaY}$ in relation to contact time, initial $\mathrm{Cr}(\mathrm{VI})$ concentration and $\mathrm{pH}$

\section{Effect of adsorbent-solution contact time}

Fig. 9 shows that the initial rate of adsorption of $\mathrm{Cr}(\mathrm{VI})$ is rapid and gradually increases till $180 \mathrm{~min}$. After reaching the equilibrium position it tends to be steady. During the initial stage of adsorption, a large number of vacant surface sites are available for adsorption. After the lapse of some time, the remaining vacant surface sites had the difficulty to become occupied due to repulsive forces between the adsorbent molecules on the solid surface and in the bulk phase. Besides, the metal ions are absorbed into the mesopores that get almost saturated with $\mathrm{Cr}$ (VI) ions during the initial stage of adsorption.

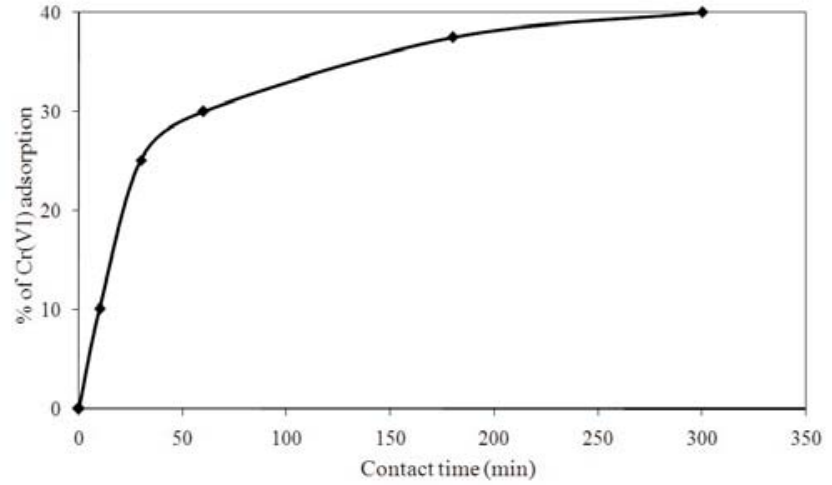

Fig. 9. Effect of contact time on the adsorption of Cr(VI) by Zeolite NaY

\section{Effect of initial Cr(VI) concentration}

Fig.10. represents the effect of initial $\mathrm{Cr}(\mathrm{VI})$ concentration on the removal of $\mathrm{Cr}(\mathrm{VI})$. Maximum adsorption was achieved in case of the lowest concentration of chromium solution used for investigation. This is because, in this case the available surface area of the adsorbent (zeolite $\mathrm{NaY}$ ) is fairly large enough and thus a better adsorption of $\mathrm{Cr}(\mathrm{VI})$ is facilitated. This indicates that in case of lower initial concentration of $\mathrm{Cr}(\mathrm{VI})$, the fractional adsorption becomes independent of initial concentrations. On the other hand, with the increase of initial concentration of $\mathrm{Cr}(\mathrm{VI})$, the adsorption efficiency decreases. Because, in case of higher concentration, the number of sodium cations of zeolite $\mathrm{NaY}$ which are neutralized by exchanging with chromium ions in the pore of zeolite framework are not enough as compared to the chromium molecules.

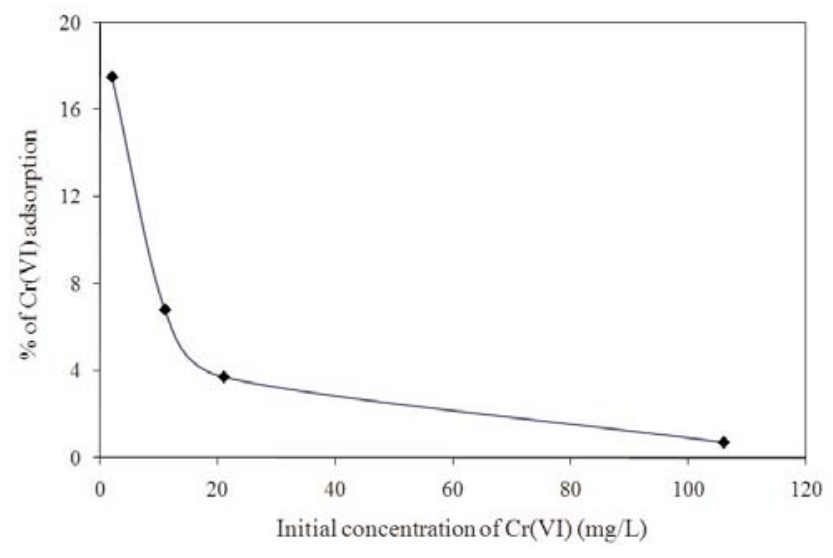

Fig. 10. Effect of initial concentration on adsorption of Cr(VI) by Zeolite

\section{Effect of $p H$}

The adsorption efficiency of the synthesized zeolite $\mathrm{NaY}$ was investigated as a function of $\mathrm{pH}$ of chromium solution. The observed result is summarized in Fig. 11 which clearly

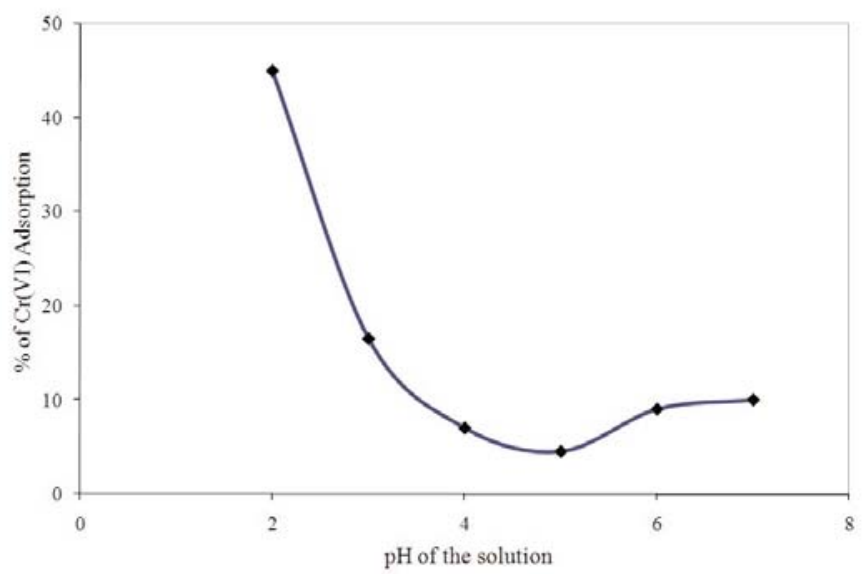

Fig. 11. Effect of pH on the adsorption of $\mathrm{Cr}(\mathrm{VI})$ by Zeolite 
shows that the acidic medium is more favourable for the adsorption. The highest adsorption was achieved at $\mathrm{pH} 2.0$ and the adsorption efficiency decreased gradually with the increase of $\mathrm{pH}$.

\section{Conclusion}

Amorphous RHA was produced by controlled burning of rice husk and this amorphous RHA was used to synthesize zeolite NaY following the seed gel and feedstock gel methods. The adsorption efficiency of the prepared zeolite $\mathrm{NaY}$ was investigated by treating the synthetic waste water containing chromium. The adsorption results revealed that after careful manipulation of the morphology, particularly the size of the zeolite as well as forming composite with other materials and methodology, zeolite $\mathrm{NaY}$ could be used as a promising cost-effective adsorbent for the treatment of waste water containing chromium. However, development of zeolite $\mathrm{NaY}$ from RHA will be beneficial in many ways, such as:

i. A cost effective and easy approach will be facilitated to remove $\mathrm{Cr}(\mathrm{VI})$ from tannery wastewater.

ii. Utilization of RHA will be a promising material recycling technology for future waste management.

iii. Pure silica produced from RHA could be used for the production of value-added materials (e.g. electronic devices, solar cells etc.) as well as in material science and environmental remediation.

\section{Acknowledgement}

The authors acknowledge the support of IGCRT, BCSIR for XRD and FT-IR analyses and CARS of the University of Dhaka for SEM analysis. We are also grateful to the Material Science Laboratory of the Department of Chemistry, University of Dhaka for allowing us to use the Tube furnace and Particle Size Analyzer (purchased under HEQEP: CP231).

\section{References}

Aderolu AZ, Iyayi EA and Onilude AA (2007), Changes in nutritional value of rice husk during trichoderma viride degradation, Bulgarian Journal of Agri. Sci. 13: 583589 .

Bajpai PK, Rao MS and Ghokhale KVGK (1978), Synthesis of mordenite type zeolite, Ind. Eng. Chem. Prod. Res. Dev. 17: 223-227.
Curkovic L, Cerjan-stefanovic S and Filipan T (1997), Metal ion exchange by natural and modified zeolites,. Water Res. 31(6): 1379-1382.

Dalal AK and Rao MS (1985), Synthesis of NaX using silica from rice husk ash, Ind. Eng. Chem. Prod. Res. Dev. 24: 465-468.

Ginter DM, Bel AT and Radke CJ (1992), The effects of gel aging on the synthesis of $\mathrm{NaY}$ zeolite from colloidal silica, Zeolite, 12(6): 742-749.

Haggerty GM and Bowman RS (1994), Sorption of chromate and other inorganic anions by organo-zeolite, Environ. Sci. Technol. 28(3): 452-458.

Jobic H (1992), Molecular motion in zeolites, Spectrochimica Acta Part A: Molecular Spectroscopy, 48(3): 293312.

Jan-Jezreel FS, Rizalinda L, Leon De, Kamolwan R, Sanchai P and Jatuporn W (2011), Properties of silica from rice husk and their utilization for zeolite Y synthesis, Quin. Novo. 34(8): 1394-1397.

Katsuki H, Furuta S, Watari T and Komarneni S (2005), ZSM-5 zeolites/porous carbon composite: Conventional-and microwave-hydrothermal synthesis from carbonized rice husk, Micropor. Mesopor. Mat. 86: 145-151.

Liu X, Yan Z, Wang H and Luo Y (2003), In-situ synthesis of NaY zeolite with coal-based kaolin, J. Nat. Gas. Chem. 12(1): 63-70.

Mier MV, Callejas RL, Gehr R, Cisneros BEJ and Alvarez PJJ (2001), Heavy metal removal with Mexican clinoptilolite multi-component ionic exchange, Water Res. 35(2): 373-378.

Park BD (2003), Characterization of anatomical features and silica distribution in rice husk using microscopic and micro-analytical techniques, Biomass Bioenerg. 25: 319-327.

Prasetyoko D, Ramli Z, Endud S, Hamdan H and Sulikowski B (2006), Conversion of rice husk ash to zeolite beta, Waste Manage. 26: 1,173-179.

Ramezanianpour AA, Khani MM and Ahmadibeni G (2009), The effect of rice husk ash on mechanical properties 
and durability of sustainable concretes, Inter. J. Civil Engg. 7(2): 83-91.

Rahman MM, Hasnida N and Wan Nik WB (2009), Preparation of zeolite $\mathrm{Y}$ using local raw material rice husk as a silica source, J. Sci. Res. 1(2): 285-291.

Riveros H and Garza C (1986), Rice husks as a source of high purity silica, J. Crys. Grow. 75: 126-131.

Roberie TG, Hildebrandt D, Creighton $\mathrm{J}$ and Gilson JP (2001), Preparation of Zeolite Catalysts, In Guisnet M and Golson JP (Eds.), Zeolites for Clean Technology. Catalytic science series, 3, 57-63, Imperial College Press, London.

Semmens MJ and Goodrich RR (1977), Biological regeneration of ammonium saturated clinoptilolite I. Initial observations, Environ. Sci. Technol. 11(3): 255-259.

Wahab OA, Nemr AE, Sikaily AE and Khaled A (2005), Use of rice husk for adsorption of direct dyes from aqueous solution: A case study of direct F. Scarlet., Egyptian J. Aqua. Res. 31(1): 1-11.
Wang H, Lin PKS, HuangYJ, Li MC and Tsaur LK (1998), Synthesis of zeolite ZSM-48 from rice husk ash, $J$. Hazard. Mater. 58: 147-152.

Williams PT and Nugranad N (2000), Comparison of products from the pyrolysis and catalytic pyrolysis of rice husks, Energy. 25: 493-513.

Wittayakun J, Khemthong P and Prayoonpokarach S (2008), Synthesis and characterization of zeolite $\mathrm{NaY}$ from rice husk silica, Korean J. Chem. Eng., 25(4): 861-864.

Received: 27 January 2013; Revised: 07 April 2013; Accepted: 21 May 2013. 